\title{
Tree Biomechanics: A White Paper from the 2012 International Meeting and Research Summit at The Morton Arboretum (Lisle, Illinois, U.S.)
}

\author{
Gregory Dahle, Jason Grabosky, Brian Kane, Jason Miesbauer, Ward Peterson, \\ Frank W. Telewski, Andrew Koeser, and Gary W. Watson
}

\begin{abstract}
The International Society of Arboriculture, in conjunction with The Morton Arboretum (Lisle, Illinois, U.S.), convened Tree Biomechanics Summit in September 2012 - bringing together a panel of internationally-recognized experts in the fields of tree biology, tree structure, structural engineering, computer modeling, and arboriculture. Following two days of public research talks on the state of tree biomechanics research, presenters were invited to attend a researcher summit to discuss persisting research gaps and prioritize research needs. Over the course of the event, summit attendees identified five priority research areas: 1) improving efforts to assess mechanical failure potential in trees; 2) modeling the impact of mechanical loading on trees; 3) understanding the mechanisms and modes of tree failure; 4) understanding tree growth response to mechanical loads; and 5) increasing the effectiveness of tree risk mitigation practices. Beyond research priorities, summit participants discussed opportunities for advancing future tree biomechanics research efforts, including the creation of a formal working group dedicated to the subject.

Key Words. Biomechanics; Failure; Mitigation; Research; Structural Behavior; Summit; Tree Failure.
\end{abstract}

Trees are a dominant part of many urban landscapes. In the United States alone, there are an estimated 3.8 billion trees in the nation's urban areas (Nowak et al. 2001). Urban trees mitigate atmospheric pollutants (e.g., carbon dioxide), abate noise pollution, filter particulate pollutants, and are associated with increased property values. When located strategically, trees also provide summer shade or function as wind breaks to reduce building energy costs. While offering these and many other benefits, trees can also pose a significant threat to critical infrastructure, commerce, property, and even life when they fail. The Chubb Personal Insurance Company estimates annual tree-related losses in the U.S. at between USD $\$ 3$ billion and $\$ 5$ billion (Jackson 2011). In its assessment of damage caused by trees, the insurer speculated that more than $75 \%$ of the trees that fail during severe weather do so as a result of pre-existing and often correctable vulnerabilities. In a similar assessment of tornado-related claims made from 2008-2012, Nationwide Insurance identified partial tree failure as the primary source of automobile damage (Giannetti 2013). While there is no crystal ball to help predict when a tree might fall, professional experience has allowed the industry to connect patterns of failure with many growth characteristics now commonly viewed as tree defects. Climatic change projections predict an increase in storm frequency and severity. If nothing is done to improve our understanding of tree stability and biomechanics in order to improve arboricultural practices, economic losses due to tree failures are likely to increase.

In September 2012, the International Society of Arboriculture and The Morton Arboretum held Tree Biomechanics Summit, which brought together internationally recognized experts in the fields of tree biology, tree structure, structural engineering, computer modeling, and arboriculture to discuss the current state of biomechanics 
research. Two broad themes permeated the planning and hosting of the event. First, there is a need to improve our current understanding of tree failure. Secondly, this knowledge must serve as a foundation for improving our best management practices for tree risk assessment and maintenance to mitigate tree failure. At the close of the summit, participants generally agreed that economic damages and loss of life due to weather induced tree failure could be reduced by improving arboricultural practices once research improves our understanding of tree stability and storm-induced failure.

To improve current risk assessment and mitigation efforts, researchers and industry professionals must understand tree structure, stability, and biomechanics. Trees with and without signs of defects or weakness can fail, and assessment methods must consider both. The participants at the Tree Biomechanics Summit identified five critical focus areas requiring research:

1. Assessing the likelihood of failure in trees

2. Modeling the impact of mechanical loading on trees

3. Understanding the mechanisms and modes of tree failure

4. Tree growth response to mechanical loads

5. Effectiveness of mitigation practices

\section{FOCUS AREA 1: ASSESSING THE LIKELIHOOD OF FAILURE IN TREES}

Likelihood of failure is determined from the moment the capacity of the tree (which is based on geometry and material properties) as well as the anticipated loads [which are related to the tree (e.g., leaf area, drag coefficient) and weather (e.g., wind velocity, gust frequency, and the type and amount of precipitation)]. Ideally, arborists would be able to assess some combination of potential applied load, tree form, strength (material properties), and degradation in stability and estimate the associated likelihood of failure for the parameters observed. This formal assessment would follow a methodological sequence, allowing the arborist to evaluate the collective strengths and weaknesses of a tree in order to estimate the likelihood of failure for the whole tree or its specific parts. Unfortunately, we have limited knowledge on many key questions, including:
* What type of average and extreme loads (static and dynamic) will a tree encounter?

* What is a desired form or structure of a given tree?

* How strong does the wood need to be?

* How extensive can decay be prior to failure?

\section{Mechanical Failure Research Priorities}

* Can we correlate observable tree defects with likelihood of failure?

* What is the relationship between root architecture and tree stability?

* Can existing data (tomography, etc.) be analyzed collectively to identify tree hazards confidence?

* What is the link between static and dynamic methods to evaluate tree strength and behavior

* Can or should we apply engineering specifications to trees?

Furthermore, we are limited by our ability to directly measure many aspects of tree stability or instability. Questions remain regarding the proper methods for assessing trees and their parts. Similarly, it is uncertain if formal protocols can be developed that link perceived strengths and inherent weaknesses (e.g., defects) directly to an increased or decreased probability of failure.

The arboriculture community has identified defects (e.g, decay, cavities, included bark, codominant branches, crack, splits) that provide a visual indication of an elevated risk of tree failure. Beyond this, little research exists to quantify the rates at which a defect increases the likelihood of failure. The ability to estimate the likelihood of failure from the severity of specific defects would improve the practice of tree risk assessment.

The ability to measure concealed defects in trees is constrained by the rate of technological advancement within arboriculture and urban forestry and our ability to adapt and apply technologies currently utilized by other fields for our purposes. The development of new tools should always be a goal for researches and practitioners. One promising technology currently used by some in the industry is tomography. As application of this technology by 
practitioners and researchers increases, it maybe possible for the data to be pooled together and more fully analyzed to provide confidence in the identification of hazards associated with internal decay or defects.

Structural behavior can be analyzed using a static or dynamic approach, which can be categorized as engineering approaches. A static approach considers loads and deformations that change in magnitude or direction over longer periods of time (e.g., accumulation of snow on branches, causing them to bend downward). A dynamic approach considers loads and deformations that change in magnitude or direction over shorter periods of time (e.g., gusts of wind bending tree branches, which sway as each gust subsides). The nature of loading determines whether a static or dynamic approach is most appropriate to assess the likelihood of failure. Static approaches are more straightforward and can provide insights into mechanical behavior. Dynamic approaches build off static ones. Understanding the link between these two methods will help in evaluating tree strength and behavior.

While an engineering approach to tree risk assessment seems promising, many engineering theories assume structures are of a uniform size and are constructed from isotropic (i.e., uniform in all directions) materials. Tree size changes with time, increasing with growth or decreasing due to dieback or damage. Similarly, the material properties of wood can change with growth stages or even location in a tree. As such, it is worth questioning where we can or should apply engineering specifications to trees. Regardless of the approach used (e.g., modeling failure associated with defects or use of engineering principles), research is needed to develop and refine the tools currently used by practitioners during risk assessments.

\section{FOCUS AREA 2: MODELING THE IMPACT OF MECHANICAL LOADING ON TREES}

Models seek to provide a mathematical description of an event in order to increase our understanding of it or predict its reoccurrence. Biomechanical models that effectively describe tree movement in wind or predict tree failure can be very useful for practitioners. However, it is often difficult for practitioners to use models as their validity is bound by the specific parameters (i.e., inputs or measure- ments) used for development. These parameters can be numerous and well beyond what is typically collected by practitioners. Similarly, models can be rendered inaccurate or invalid when applied to new species, soil conditions, loadings, or unusual combinations of factors. Models are generally modified with growing experience, empirical testing, crossvalidation, and the debate that ensues when they fail to explain events within their designed purpose. For models to be useful for tree care practitioners and managers, they must distill complex phenomena down to a smaller number of essential components. Yet potentially important factors can be left out that limit the strength of the models. Establishing sufficient and relevant model parameters can be daunting due to logistic challenges and limited opportunities to test large trees prior to failure. The challenge of data collection before failure to inform models was most apparent to the researchers and practitioners at the biomechanics research summit.

\section{Load Modeling Research Priorities}

* Can forestry models of wind stability be applied to the urban environment?

* How do forces or energy move through the tree?

* Can wind benefit trees in the urban environment?

* Can we predict probability of wind events?

* Can we define an optimum natural branch form?

Developing and validating biomechanical models remains a critical component in understanding and communicating the balance of ecosystem services and values trees provide against their risk in severe weather events. Supporting tree risk management decisions with both biological and mechanical research remains an underdeveloped area within the tree care profession. Our limited understanding in the face of staggering permutations of species, environmental loads, and levels of wood degradation from decay suggests a need for coordinated and robust research. Physical and mechanical models tend to dominate current tree biomechanics efforts to organize the more vari- 
able and lesser understood biological responses of trees. Many tree biomechanical models seek to describe a critical instance producing failure. The intent is to both organize and segregate the mechanical and the biological aspects of failure in order to explain the physics governing tree and wood behavior. Once defined, departures from model expectations can be helpful in addressing the variability associated with different species and individuals within species for specific situations.

Four modeling challenges assume higher priority for open-grown trees. First, there are very few empirical data to describe the important mechanical parameters (drag coefficient, natural frequency, damping ratio, moduli of elasticity and rupture, etc.) necessary to build models to predict failure. (This is exacerbated by the logistic challenges of and available opportunities to test appropriate specimens.) Second, crown and root architecture of open-grown trees have not been adequately quantified. This is especially true given the inherent variability in crown and root architecture of trees growing in developed landscapes, where maintenance (e.g., cabling and pruning) and above- and belowground restrictions on growth add to the inherent variability. The complex crown and root architecture of amenity trees makes it difficult to assume some of the mechanical parameters necessary to assess the likelihood of failure, such as drag coefficient, crown area or volume, natural frequency, damping ratio, and critical overturning moment. Third, maintenance practices and ontogenetic changes to relevant mechanical parameters (e.g., wood properties, defects, and crown and root architecture) undermine the application of simple models to assess the likelihood of failure beyond short timeframes. There are other aspects of the growth of open-grown trees (e.g., changes to wood properties and defects over time) that are similarly difficult to assume because they are inherently variable and have not been adequately quantified. Fourth, wind flow around open-grown trees in developed landscapes is complicated and has not been adequately quantified.

Modeling approaches are desired, speaking to the difference between the biological understanding of trees and their informed risk management. An urban forest manager seeks a discrete number of measures to better commu- nicate and appraise the likelihood of failure. To do so, applied tree biomechanical models are often rooted in dynamics of movement resulting from wind or water loads. These models often use static tests to appraise stability as a surrogate diagnostic measure. Such models can then be deployed for an individual tree, client property, or community for management prioritization and emergency planning. There is a research and development community focused on strategic applied modeling and measurement, yielding innovative tools and approaches. There also is a wide range of basic research modeling toward understanding community patterns from disturbances, natural acclimations, and ecological function gaining significance within a changing climate marked by extreme weather patterns.

There are many tools used in modeling research and field diagnostics that provide highly accurate data at a high rate of measurement. The pace at which newer, more precise tools enter the market often outstrips the critical testing and interpretation needed to gauge the usefulness of the data collected. There remains a lack of integrated research testing across regions, and effort can be characterized as localized activity defined by the commercial tools in use on limited species. Equipment and training costs govern the rate of tool adoption to provide generalized service or research capacity. Prohibitive tool costs often limit adoption to experienced consultants with specialized training, as the tools are beyond the financial reach and therefore irrelevant to most practicing arborists. Additionally, there is limited efficacy in feeding highly refined tool-specific data into models where other parameters are roughly estimated. The opportunity does exist, however, to crowdsource data and aggregate existing public domain data streams to inform fully integrated models across species, regions, and time.

\section{FOCUS AREA 3: UNDERSTANDING THE MECHANISIMS AND MODES OF FAILURE IN TREES}

Tree failure from wind, rain, ice, and snow is common in natural and urban landscapes. Typically, the strongest external loads that trees experience are caused by wind. When wind events are accompanied by precipitation, the likelihood of tree failure increases. 
Failure Mechanism Research Priorities

* What are the most common mechanisms of failure?

* What are the failure mechanisms associated with specific defect types?

* Is there species variation in failure mechanisms?

* How do the environmental factors affect failure mechanisms?

* What factors are involved in Sudden Branch Drop?

* Can we calculate a safety factor for anchorage that accounts for variations in soil moisture conditions?

Urban soil conditions, such as soil compaction, poor soil structure, and lack of water, oxygen, and nutrients severely limit root system growth. Barriers, such as curbs, pavement, and retaining walls prohibit horizontal root expansion. Lifelong structural weaknesses in root systems can begin in the nursery as a consequence of production practices. For example, lateral root growth in container-grown trees is impeded by the container walls. As they grow outward, roots are deflected down in a circling pattern or kink back in toward the trunk. As roots grow and become woody, permanent defects are created that reduce stability. When planted in the landscape, these compact, circling root systems are partially responsible for uprooting during strong storms.

Decay compromises the structural integrity of trees and predisposes them to failure. Susceptibility to decay and the rate of decay progression in trees varies greatly by species and environmental conditions. Future research should investigate how cultural practices, such as pruning, affect likelihood of attack by decay, causing fungi at the species level, and attempt to quantify strength loss based on the species of tree and decay-causing organism.

Poor tree structure, including defects such as codominant stems and included bark, increase the likelihood of branch and crown failure. Targeted pruning can improve tree structure and reduce crown exposure to natural forces. Reduction pruning of branches slows their growth rate. This helps decrease the branch-to-trunk diameter ratio (aspect ratio) over time. Branches with a lower aspect ratio tend to be strongly attached to the trunk. Conversely, branches with a large aspect ratio and codominant stems are more weakly attached to the tree. Codominant stems often have a narrow angle of attachment and tend to develop bark inclusions, which further reduces attachment strength. Codominant stem failure is one of the most common types of crown and branch failure of urban trees. More work is needed to develop models that help practitioners predict attachment strength based on visible external characteristics such as aspect ratio and included bark.

Numerous studies have catalogued tree damage following storms. Most have focused on categorizing species susceptibility to failure by ranking them into damage categories (e.g., high, medium, and low). Although reports of susceptibility by species vary greatly, certain factors, such as weak wood (i.e., low modulus of elasticity/modulus of rupture) and poor form (e.g., trees with a tendency to produce codominant stem or have branches with narrow angles of attachment), may predispose some species to storm damage. Post hoc storm damage surveys are often limited, however, because important characteristics, such as branch orientation, morphometric data, and presence of decay are often lost during clean-up operations. Capturing this data would help researchers improve methodologies in studies that examine failure mechanisms.

Summer branch drop (SBD) (aka sudden branch drop) is the phenomenon where seemingly healthy, undamaged branches break and fall from trees, usually on hot, dry, calm summer afternoons. Breakage usually occurs away from the branch union. The exact mechanism for SBD is unclear, though it is believed that water loss through transpiration is involved. The literature is apparently devoid of empirically tested SBD, presumably because the random nature of the phenomenon makes it almost impossible to predict when it will occur. Having a better understanding of the failure mechanisms involved with SBD could lead to preventive treatments that help minimize this phenomenon.

Although researchers have employed static and dynamic tests to measure forces on trees, there is little information on how these forces translate into natural forces that act on landscape trees. Research relating the forces exerted on trees from 
static and dynamic tests to natural loading events are needed to develop more accurate assessments of natural forces that cause failure. Windinduced tree sway also induces torsional stress on branches. However, there is insufficient information on the effects of torsion on tree or branch failure.

\section{FOCUS AREA 4: TREE GROWTH} RESPONSE TO MECHANICAL LOADS

Around 300 B.C., the Greek philosopher Theophrastus noted that trees growing in windy environments were shorter in height, had shorter internodes (more knots), grew less straight, and had a closer wood grain (developing harder wood). The first experiments on the influence of wind on tree growth were published in 1803 (Knight 1803). Trees that were staked to prevent wind-induced sway grew taller, were thinner in diameter, and weaker than the non-staked trees. The mechanical action of wind reduces height growth while increasing radial growth. This results in a tree of shorter stature, but a thicker trunk (increased stem taper) and decreases the amount of wind-induce drag experienced by a tree. Thigmomorphogenesis is the term now used to describe the growth response plants exhibit to external mechanical stimuli.

\section{Growth Response Research Priorities}

* What are the long-term effects of pruning or storm-induced changes in structure on acclimative growth and biomechanics of the remaining structure?

* How can strength and speed of response growth tissue be optimized?

* How effective is response growth in compensating for structural defects?

* How do trees acclimate to changes in the surrounding environment?

In order to understand the implications of thigmomorphogenesis on trees and tree stability, it might be useful to compare a living tree with an engineered structure. An engineered structure, such as a bridge span, is designed to support a given load and resists bending through internal strains (compressive and tensile) created in the span at the time it is manufactured. Trees also produce internal growth strains within its newly forming wood in response to the external mechanical loads they experience. These include both stresses due to the push of wind and the pull of gravity, including additional loading from ice and snow or fruit. Should the load on the bridge span gradually increase beyond design limits, the bridge would not be able to support the additional load and would eventually fail. Unlike the bridge span, the tree is dynamic and constantly growing. A tree is able to perceive an increase in mechanical loading and respond by adding a new layer of wood with specific characteristics required to alter the internal growth strains required in response to the increased loading.

Trees are able to perceive mechanical loads (mechanoperception) and respond physiologically and developmentally (thigmomorphogenesis). When the plant cell is put under a mechanical load, the force is perceived by the cell and forms a complex series of metabolic responses that trigger an increase in cell division in the vascular cambium resulting in an increase in radial growth. The resulting growth form, both aboveand belowground, and wood formed by the tree in response to wind or other mechanical loading, is now better acclimated to deal with future mechanical loads. Consequently, the tree is more stable than it would have been had it not experienced the mechanical load of the wind. This is an important concept that can be further applied to landscape, nursery, and arboricultural practices.

It is imperative that a better understanding of how trees with altered or damaged crowns, trunks, or roots respond to their mechanical environment. This includes determining how pruning or storminduced changes in crown and root structure affect new growth of the remaining tree. How long will it take the tree to regain stability, to reach a new equilibrium with regard to its new environment? Is there an age limit to which a tree can fully respond and recover mechanical strength? Is gradual pruning or thinning better for the mechanical stability of a tree than radical pruning? If neighboring trees are removed, is the remaining tree or trees more susceptible to future damage or failure? Can we stimulate and accelerate the acclimation process through practice or with treatments without 
compromising other structural, aesthetic, or physiological elements of the tree? It is a basic tenant of fracture mechanics that once a fracture occurs, it cannot be stopped. This is particularly true in trees. The insertion of rods across the fracture zone can stabilize the fracture, but does it alter the ability of the tree to respond to additional mechanical loads? How does cabling alter canopy and branch development and does it significantly alter the ability of a tree to absorb wind energy and reduce oscillation via damping? Does cabling significantly alter branch and branch union strength similar to how staking compromises tree stability to wind and ability to respond to future loading?

Answers to these important questions can provide an improved understanding of how arboricultural practices impact tree strength and resilience. Some of the critical information needed to address these questions already exists in part, but is likely to be found in the forestry, ecology, and tree physiology literature. Combined with well-designed research studies and careful field observation, existing data could be applied to accurate models of tree growth and response to mechanical loads to determine the limits to which we should treat our trees. Such models might even provide a better predictor of how long it will take for a tree to regain its stability.

\section{FOCUS AREA 5: EFFECTIVE- NESS OF MITIGATION PRACTICES}

The biomechanical implications of many arboricultural practices are not well understood. Arboricultural practices, such as pruning and cabling, have mechanical consequences on trees and are often intended to reduce the likelihood of tree failure. Changes to drag, moments (the product of force and lever), stresses, oscillatory frequency, and damping all may result from pruning and cabling, but too few empirical data exist to draw robust conclusions and validate theoretical or numerical models. A greater breadth and depth of understanding of tree biomechanics exists for trees of excurrent form (exemplified by forest- or plantation-grown conifers), but investigations considering trees of decurrent form are less common and often involve small trees. Larger trees do not necessarily have the same allometry or behave the same mechanically as smaller trees, hence scaling up results can be problematic.

\section{Mitigation Research Priorities}

* Will pruning to alter crown architecture reduce the likelihood of failure?

* Can crown pruning alter root/soil plate movement?

* Does cabling reduce the failure rate of codominant stems?

* Are support systems properly designed to mitigate biomechanical weaknesses in trees?

* Does pruning enhance safety?

There is general agreement that regardless of the location from which biomass is removed pruning reduces drag in approximate proportion with biomass removed. However, the location from which biomass is removed can alter the effect of pruning on bending and twisting moments. Crown raising can increase the lever on a tree, while crown reduction decreases it. Consequently, the bending moment, which is the product of drag and lever, is more effectively decreased through reduction pruning, as experiments have shown. Since the effect of thinning on the shape of a crown is usually negligible, it decreases bending moment primarily by decreasing drag. Several questions remain, however, since the mechanical analysis cannot ignore biological reality. Reduction pruning-while effective in reducing drag, bending moment and bending stress-may ultimately increase stress if trees sprout vigorously and decay rapidly in response to the pruning.

Using a static analysis, which has been historically more common, cannot easily investigate the true effectiveness of pruning on reducing the likelihood of failure because the interaction of wind and tree is dynamic. Consistent with dynamic beam theory, the natural sway frequency of trees of excurrent form can be approximated by the ratio of DBH to the square of tree height. This model, however, does not hold for trees of decurrent form, presumably because the complex crown architecture of such trees induces a multi-modal dynamic response. Mass participation of the trunk and larger branches can affect the frequency. Predicting the damping ratio of trees of either excurrent or decurrent form has been gener- 
ally attributed to mass or structural damping (the movement of branches within a crown independent of the trunk) and aerodynamic drag on leaves.

Of the few studies that have investigated the effect of pruning on the sway response of trees, changes to the mass and aerodynamic drag of the tree alter the frequency in somewhat predictable ways. The effect of leaves, however, supersedes the effect of pruning. Similarly, leafless trees experience greater reduction in drag and bending moment than typical pruning doses achieved. The effect of pruning on trees of decurrent form requires considerably more empirical work, which should help validate existing finite element models. None of the work on pruning has specifically investigated movement of the root plate and soil.

Installing support systems is another common arboricultural practice intended to reduce the likelihood of tree failure, but there is minimal research to confirm this. Installing brace rods can change the location of failure of codominant stems (i.e., forked branches nearly equal in size, often with included bark) to immediately above the hardware, but this effect has not been confirmed with studies on cables or large trees. Some opinions suggest that installing support systems (especially those made of steel) alters tree growth in accordance with the hypothesis of acclimative growth, but a recent experiment testing steel and synthetic cables did not support this speculation. Installing steel cables in red oaks increased natural frequency, but not damping. Once again, the effect of leaves superseded the effect of the cable, and leaves did increase damping, regardless of whether a cable had been installed.

Many of the conventions of the biomechanical effects of arboricultural practice are based on simple mechanical approaches which, while intuitive, neglect to consider the complex crown architecture of a typical open-grown tree. For example, leaves increase damping and drag, but decrease frequency. These outcomes theoretically offset one another to some degree: reduced frequency and greater drag mean greater bending stress, but greater damping allows trees to shed wind energy. A recent finite element model using Monte Carlo simulations illustrated the complexity of such competing effects: of two modeled sugar maples (Acer Saccharum), one was more likely to fail while leafless, while the other was more likely to fail when it was in leaf. The simple mechanical approaches are conceptually useful, but without substantially more experimental observations, their practical application is tenuous.

\section{ADVANCING TREE BIOMECHANICS RESEARCH}

There are a growing number of talented scientists interested in tree biomechanics research, but as is so often the case in arboriculture and urban forestry, resources to support research are often limited. Collaboration, technology and knowledge transfer, and funding are strongly linked and are important to generating new knowledge through research.

\section{Collaboration}

Collaboration is the fastest and most efficient way to develop and build our understanding of tree biomechanics. Teams working together can often accomplish more than the same individuals working separately. Collaboration encourages exploring and sharing new ideas, and larger, more comprehensive projects. This collaboration will benefit arborists, researchers, the tree care industry, property owners, and trees. A Tree Biomechanics Working Group or collaboration needs to be developed to advance large projects. This would be best housed in an existing arboricultural or academic association.

Joint research projects, conferences, and events that allow sufficient time for informal discussions have opened communication channels and fostered further collaboration among tree biomechanics researchers within the field. However, greater attention does need to be given to working and creating links with researchers from other disciplines, such as forestry, engineering, physics, forestbiology, wood products, biofuels, storm water, horticulture, and pomology. The benefits of multidisciplinary research were recently illustrated by the successful application of National Aeronautics and Space Administration-developed technology in measuring surface strains to evaluate stress in trees and branches. Beyond collaboration among academics, the inclusion of practicing arborists as contributors to the research processisjust starting to be explored by researchers. This mix of researchers 
and professionals was adopted during both of the Tree Biomechanics Week of Research events (Davey Research Farm, Shalersville, Ohio, U.S.) and has the potential to spur novel research while growing the industry's appreciation for research.

\section{Technology Transfer}

Research and technological advances are valuable if they are used. As such, biomechanics research needs to be applied by practitioners to make a difference to trees, people and arborists. The more knowledge is shared and used, the more valuable it becomes. The basic or overall objective of technology or knowledge transfer in tree biomechanics is to help professionals and the public understand what makes a tree strong and safe, when the risk associated with a tree is raised to a level deemed unacceptable, and what can be done to help trees stay strong.

There is a substantial and rapidly growing body of biomechanical knowledge for trees. Finding ways to speed the transfer of this information to practitioners and the public effectively will

1. improve the safety of trees, particularly large trees

2. improved tree care results and the work of arborists

3. increase support and funding both for more research and for more tree care

4. improve the return on the research investment when more people use the information

5. make more effective arborists with better knowledge and tools

During a facilitated discussion session with symposium attendees, practitioners clearly stated the need for simple, consistent answers and guidelines for identifying and mitigating risk factors. While written scientific papers are the definitive source of new research, they have a limited but knowledgeable audience. Information should be reformatted for more general distribution in professional journals, magazines, and trade organization newsletters, and general print and electronic media. Colleges, universities, and technical schools are primaryinitial sources of education and training for professionals. Once in the profession, many practitioners rely on profes- sional organizations or cooperative extension services for continuing their professional development.

The current missing piece is who will package the information for these sources? Who will promote taking the data and information from research and scientific papers, and translate it into applied technology. Who will create and relay knowledge that will reach more people and make more of a difference. It is easy to point out what needs to be done; it takes much more work to actually do it.

\section{Funding}

Traditional sources of funding for arboricultural biomechanics, and all of arboricultural research, are limited. Non-traditional sources of funding need to be developed from groups that would use and benefit from the results. A national or international collaborative program may generate the greatest interest within private sector (insurance, utility, transportation) and government agencies with a vested interest in mitigating tree-induced losses. These should be organizations that have resources to contribute, could use the results, and have a process to contribute the support. Collaborative research and funding can provide individual funders with more significant results by sharing the cost of the research with otherfunders and by sharing the results.

Arboricultural biomechanics is a relatively new discipline, and it requires basic research as a foundation for the applied research that follows. A needs analysis would demonstrate the value of increased research-based knowledge to users. There needs to be a description of deliverables that illustrates what will be learned with the funding and how those findings will be used. This has to show clearly what can be accomplished with the research funding. The potential results would need to be compelling enough to attract the attention of some of the larger research funding organizations. 


\section{LITERATURE CITED}

Giannetti, E. 2013. Falling Trees, Flying Branches Kick Start Damage During Tornadoes. Nationwide Insurance Press Release. Accessed 04/08/2014. <www.nationwide.com/about-us/030513severe-weather-week.jsp>

Jackson, K.L. 2011. Hurricane Irene: Ailing Trees Can Cause Major Damage in Tropical Storms. The Star Ledger. Accessed 04/08/2014. <www.nj.com/homegarden/index.ssf/2011/09/ hurricane_irene_ailing_trees_c.html>

Knight, T. 1803. Account of some experiments on the descent of sap in trees. Philosophical Transactions of the Royal Society of London. 93:277-289.

Nowak, D.J., M.H. Noble, S.M. Sisinni, and J.F. Dwyer. 2001. PAssessing the U.S. Urban Forest Resource. Journal of Forestry 99(3):37-42.

Gregory Dahle (corresponding author)

West Virginia University

Morgantown, West Virginia, U.S.

Jason Grabosky

Rutgers University

New Brunswick, New Jersey, U.S.

Brian Kane

University of Massachusetts-Amherst

Amherst, Massachusetts, U.S.

Jason Miesbauer

The Morton Arboretum

Lisle, Illinois, U.S.

Ward Peterson

Davey Resource Group

Kent Ohio

Frank W. Telewski

Michigan State University

East Lansing, Michigan, U.S.

Andrew Koeser

University of Florida Gulf Coast Research and Education Center

Wimauma, Florida, U.S.

Gary W. Watson

The Morton Arboretum

Lisle, Illinois, U.S.
Zusammenfassung. Die ISA hat im September 2012 in Zusammenarbeit mit dem Morton Arboretum das Baum-BiomechanikGipfeltreffen zusammengerufen und ein Forum von international anerkannten Experten im Bereich von Baumbiologie, Baumstruktur, struktureller Gestaltung, Computer Modeling und Arboristik zusammengebracht. Nach zwei Tagen mit öffentlichen Vorträgen über den Status der Erforschung von Baummechanik, wurden die Präsentierenden eingeladen, an einem Forschergipfel teilzunehmen, um die bestehenden Forschungslücken zu diskutieren und Forschungsanforderungen zu priorisieren. Im Verlauf der Veranstaltung identifizierten die Gipfelteilnehmer fünf vorrangige Forschungsbereiche: 1.) Verbesserung der Bemühungen, das mechanische Versagenspotential in Bäumen zu untersuchen; 2.) Entwicklung von Modeln zum Einfluss mechanischer Last auf Bäume; 3.) Verständnis der Mechanismen und Arten des Baumversagens; 4.) Verständnis für das Verhältnis von Baumwachstum zu mechanischer Last und 5.) Verstärkung der Effektivität zur Verringerung von Baumrisiken. Abgesehen von den Forschungsprioritäten diskutierten die Gipfelteilnehmer Möglichkeiten der fortschrittlichen zukünftigen Forschungsbemühungen in der Baummechanik einschließlich der Gründung einer formalen Arbeitsgruppe zu diesem Thema.

Résumé. La Société Internationale d'Arboriculture, en collaboration avec l'arboretum Morton (Lisle, Illinois, États-Unis), a organisé un sommet sur la biomécanique de l'Arbre en septembre 2012, réunissant un panel d'experts de renommée internationale dans les domaines de la biologie de l'arbre, de la structure de l'arbre, de l'ingénierie structurelle, de la modélisation informatique et de l'arboriculture. Après deux jours d'échanges sur la recherche en biomécanique de l'arbre, les participants ont été invités à participer à un sommet où les chercheurs discutèrent des lacunes majeures en recherche et établirent les priorités d'investigation. En cours d'événement, les participants au sommet identifièrent cinq domaines prioritaires de recherche: 1) l'amélioration des efforts visant à évaluer le potentiel de défaillance mécanique chez les arbres; 2) la modélisation des impacts de la charge mécanique sur les arbres; 3 ) comprendre les mécanismes et les modes de défaillance des arbres; 4 ) comprendre la croissance réactive en lien avec les charges mécaniques exercées; et 5) augmenter l'efficacité des mesures d'atténuation des risques présentés par les arbres. Au-delà des priorités de la recherche, les participants au sommet ont discuté des possibilités de faire progresser les efforts en recherche sur la biomécanique des arbres, y compris la création d'un groupe formel de travail dédié à ce sujet.

Resumen. La Sociedad Internacional de Arboricultura, en conjunto con The Morton Arboretum (Lisle, Illinois, Estados Unidos), convocó la Convención sobre la Biomecánica del Árbol en septiembre de 2012 - reuniendo a un grupo de expertos reconocidos internacionalmente en los campos de la biología del árbol, estructura de árbol, ingeniería estructural, modelado por computadora y arboricultura. Después de dos días de intervenciones públicas sobre el estado de la investigación biomecánica de los árboles, se invitó a los presentadores a asistir a una cumbre para discutir las deficiencias persistentes de investigación y priorizar las necesidades. En el transcurso del evento, los asistentes identificaron cinco áreas prioritarias de investigación: 1) la mejora de los esfuerzos para evaluar el potencial de falla mecánica en los árboles; 2) modelar el impacto de la carga mecánica en los árboles; 3) la comprensión de los mecanismos y modos de falla del árbol; 4) entendimiento de la respuesta en crecimiento del árbol sometido a cargas mecánicas; y 5) el aumento de la eficacia de las prácticas de mitigación de riesgo de árboles. Más allá de las prioridades de investigación, los participantes de la cumbre discutieron las oportunidades para avanzar en los esfuerzos futuros de investigación en biomecánica de los árboles, incluyendo la creación de un grupo de trabajo oficial dedicado al tema. 